\title{
Preoperative Oral Sedation with Midazolam and Paracetamol vs Sedation Nasally with Midazolam and Ketamine for Children Scheduled for Dental Treatment
}

\author{
Walid Y. Kamel, Aktham A. Shoukry \\ Department of Anaesthesia, ICU and Pain Management, Faculty of Medicine, Ain Shams University, Cairo, Egypt \\ Email:walid_yousofkamel@yahoo.com,aktham.shoukry1@gmail.com
}

\begin{abstract}
How to cite this paper: Kamel, W.Y. and Shoukry, A.A. (2017) Preoperative Oral Sedation with Midazolam and Paracetamol vs Sedation Nasally with Midazolam and Ketamine for Children Scheduled for Dental Treatment. Open Journal of Anesthesiology, 7, 184-193.
\end{abstract}

https://doi.org/10.4236/ojanes.2017.77020

Received: June 26, 2017

Accepted: July 23, 2017

Published: July 26, 2017

Copyright $\odot 2017$ by authors and Scientific Research Publishing Inc. This work is licensed under the Creative Commons Attribution International License (CC BY 4.0).

http://creativecommons.org/licenses/by/4.0/

\section{(c) (i) Open Access}

\begin{abstract}
Background: Preoperative anxiety is common among children. It can result in adverse physiological and psychological outcomes. Pharmacological and non-pharmacologic techniques used preoperatively to decrease anxiety and improve cooperation in pediatric patients. The extent of an individual child's risk for stress reflects genetics, personality, parenting, and previous life experience. Children 1 to 5 years of age are at the highest risk for extreme preoperative anxiety. Material and methods. The study is a double blinded clinical trial that conducted in Ain Sham University on 90 children for pulpotomy in the period from august 2015 to may 2017 after approval of the ethical committee and informed written consent from the guardians. The patients were divided randomly into two groups. Fifteen min. before the procedure, $\underline{I n}$ group $O$, midazolam/paracetamol at a dose of 0.5 and $15 \mathrm{mg} / \mathrm{kg}$ respectively was given orally. In group $N$, midazolam/Ketamine $0.5 \mathrm{mg} / \mathrm{kg}$ and $10 \mathrm{mg} / \mathrm{kg}$ sprayed nasally. Ramsay sedation scale, child separation, mask acceptance, Aldrete's scoring system, postanesthetic discharge criteria and parent satisfaction scores were recorded. Results. group $\mathrm{N}$ showed more smooth parenteral separation [ 88.9 vs $8.9 \%$ ] and better tolerance to the face mask "scale 1' [73.3\% vs 22.2\%] meanwhile the PACU discharge [88.9\% vs $66.7 \%$ ] and the hospital discharge [77.8\% vs 46.7\%] were earlier in group $\mathrm{O}$ with a higher satisfaction score [77.7\% vs 22.2\%]. Conclusion: The combination of midazo$\mathrm{lam} /$ paracetamol is orally comparable to the combination of midazolam/ketamine nasally; however "midazolam/paracetamol" achieves a higher parents satisfaction and earlier postoperative discharge.
\end{abstract}

\section{Keywords}

Sedation, Children, Discharge, Dental, Oral, Nasal 


\section{Introduction}

Preoperative anxiety is common among children undergoing surgery [1] and can result in heroic events especially physiological as well as psychological [2]. Children with preoperative anxiety are more likely to exhibit signs of emergence delirium and to develop behavioral changes in the postoperative periods [3] [4]. These children also present with postoperative pain and require strict pain control [2].

Many reasons to make the children calm preoperatively have been described; it is generally accepted that anxiolysis is the main goal [5] [6] and that benzodiazepines are the first choice and more frequently used [7] [8] [9].

Anxiolytic-sedative agents are used preoperatively for a long time [5]. Twenty years ago, it was already concluded that "much was unclear about the intended effects, choice of optimal agents, patient selection, and effectiveness" [6]. Till the present time the same can be concluded [10].

Pharmacological as well as non-pharmacologic techniques were used in the preoperative time to decrease anxiety and improve cooperation in pediatric patients preoperatively [11].

Many approaches can be used to achieve anxiolysis in children perioperatively. The most common techniques for anxiolysis include the administration of a sedative drug and parental attendance during the induction. These techniques may be used alone or in combination to achieve the target [12].

The causes of bad behaviors in children postoperatively include physiologic compromise such as metabolic disturbances, hypoxemia or bladder distension. Such complications are however possible to diagnose. Among the variables, pain poses a diagnostic dilemma [13]. Behavioral signs of emergence agitation often mimic those of postoperative pain [14].

The aim of this study is to assess the effect of two different pharmacological agents combined with midazolam on the child separation, level of separation and hospital discharge.

\section{Material and Method}

The study is a double blinded clinical trial that was conducted in Ainshams University hospital on 90 children scheduled for tooth pulpotomy after approval of the ethical committee and informed written consent from the guardians.

The patients were randomly divided into two equal groups [group $O$ and group $N$ ].

In group $O$, the patient received midazolam orally [ $\mathrm{Rx}$ Dormicum $5 \mathrm{mg} / \mathrm{ml}$ ] at a dose $0.5 \mathrm{mg} / \mathrm{kg}$ diluted in paracetamol [Rx Cetal $250 \mathrm{mg} / \mathrm{ml}$ ] at a dose of 15 $\mathrm{mg} / \mathrm{kg}$ and $2 \mathrm{ml}$ of water given to the patient $15 \mathrm{~min}$ before the procedure by drinking. In group $N$, midazolam [Rx Dormicum $5 \mathrm{mg} / \mathrm{ml}$ ] at a dose $0.5 \mathrm{mg} / \mathrm{kg}$ and Ketamine [Rx Ketamax-50 $50 \mathrm{mg} / \mathrm{ml}$ ] at a dose of $10 \mathrm{mg} / \mathrm{kg}$ sprayed nasally to the patient $15 \mathrm{~min}$. before the procedure.

On patient admission, the patient was clinically and laboratory [lab.] eva- 
luated. Lab. evaluation was including complete blood count and coagulation profile.

\section{Inclusion criteria:}

- The patients who were clinically free or with controlled medical condition [ASA I or ASA II]

- Age between 2 to 6 years Exclusion criteria:

- ASA III or ASA IV

- Age greater than 6 years

- Guardians' refusal to participate in the study.

- In appropriate level of sedation

- Patients with obstructive sleep apnea

Fifteen minutes later, the level of sedation was recorded as well as the child separation score after the patient transferred to the operating room on a troll.

Anaesthesia was conducted by inhalational induction ( $\mathrm{Rx}$ sevoflurane), face mask acceptance scale was recorded. Intravenous access (Wellcath) was inserted and secured and muscle relaxant Atracurium ( $R x$ Atracurium hameln) was injected at a dose $0.5 \mathrm{mg} / \mathrm{ml}$.

Airway was then intubated nasally by a RAE nasal endotracheal tube ( $\mathrm{Rx}$ Flexicare) based on the child age, the child was then mechanical ventilated by pressure mode.

After induction of anaesthesia, local anaesthetic articaine hydrochloride $4 \%$ with epinephrine 1:200,000 ( $\mathrm{Rx}$ Astracaine) was injected by the dentist,

The standard monitor includes electrocardiograph [ECG], pulse oximetry [SPO2], non-invasive blood pressure [NIBP] and capnography. Anaesthesia was then maintained by sevoflurane and a bolus dose of atracurium was injected at a dose $0.1 \mathrm{mg} / \mathrm{ml}$ every $20 \mathrm{~min}$. After the patient extubation, the patients were transferred to the PACU where the Aldrete's scoring system was calculated and recorded at $10 \mathrm{~min}$. time interval. By the time the Aldete's scoring system got equal or more than 9 , the patient discharged to the ward. During the patient stay in the ward the discharge criteria will be calculated accordingly at $15 \mathrm{~min}$. time scale, and the patient discharged home by the time the discharge criteria was equal to or greater than 9.

\section{Results}

\subsection{Sample Size and Statistical Analysis}

With respect to sample size calculation, it was calculated using PS [version 3.0.43, Department of Biostatistics, Vanderbilt University, located in Nashville, United States], Based upon the assumption that adding ketamine or paracetamol to midazolam decrease the preoperative child anxiety by $20 \%$ and taking power $(1-\beta)$ at 0.8 and alpha error 0.05 , and based on a results from a previous study and on non inferiority study hypothesis, minimum sample size of 45 patients was calculated for each group. The primary end point of this study is to achieve 
acceptable level of sedation for child separation, while the secondary end point will be early hospital discharge in day care dental surgery in pediatric patients.

Statistical analysis was performed using computer software statistical package for the social science [SPSS, version 20; SPSS Inc., Chicago, Illinois, USA]. Description of quantitative [numerical] variables was performed in the form of mean \pm SD. Description of qualitative [categorical] data was performed in the form of number of cases and percent. Chi-square is the hypothesis that the row and column variables are independent, without indicating strength or direction of the relationship. Pearson chi-square and likelihood-ratio chi-square, Fisher's exact test and Yates' corrected chi-square are computed for $2 \times 2$ tables.

The two groups were comparable as regarding the age, gender and ASA classification with the patients in the two groups underwent the same procedure [Table 1], after $15 \mathrm{~min}$. from the initiation of the study, the level of sedation were assessed in both groups by Ramsay sedation scale, the patients in group $\mathrm{N}$ achieved a deeper level of sedation "could respond to commands" $75.6 \%$ in group $\mathrm{N}$ vs $37.8 \%$ in group $\mathrm{O}$ [Table 2].

Assessment of the child separation by the child separation scale revealed that most of the patients in group $\mathrm{N}$ were calm and easily separated, [88.9\%] vs. [8.9\%] in group $\mathrm{O}$, meanwhile $86.7 \%$ of the patients in group $\mathrm{O}$ were also separated but with whimpering and assurance, 3 patients were crying and couldn't be easily separated, one of them were in group $\mathrm{N}$, those patients were excluded and replaced by others [Table 3].

The acceptance of the face mask during the induction of the anesthesia was evaluated and it shows a highly significant statistical difference between both groups where [73.3\% of the patients in Group $\mathrm{N}$ were calm, cooperative, or asleep vs $22.2 \%$ in group O], on the other hand $68.9 \%$ of the patients in group $\mathrm{O}$ showed moderate fear of the mask but they could be easily assured [Table 4].

Table 1. Demographic data showing that the two groups were comparable as regarding gender, age and ASA classification.

\begin{tabular}{ccccccccc}
\hline & \multicolumn{2}{c}{ Group O } & \multicolumn{2}{c}{ Group N } & \multicolumn{2}{c}{ Total } & \multicolumn{2}{c}{ Chi-square } \\
\cline { 2 - 8 } & $\mathrm{n}$ & $\%$ & $\mathrm{n}$ & $\%$ & $\mathrm{n}$ & $\%$ & $\mathrm{X}^{2}$ & P-value \\
\hline Male & 20 & 44.44 & 22 & 48.89 & 42 & 46.67 & & \\
Female & 25 & 55.56 & 23 & 51.11 & 48 & 53.33 & & 0.179 \\
& & & & Age & & & & \\
2 yrs. & 3 & 6.67 & 2 & 4.44 & 5 & 5.56 & & \\
3 yrs. & 6 & 13.33 & 5 & 11.11 & 11 & 12.22 & & \\
4 yrs. & 14 & 31.11 & 16 & 35.56 & 30 & 33.33 & 0.983 & \\
5 yrs. & 15 & 33.33 & 17 & 37.78 & 32 & 35.56 & & \\
6 yrs. & 7 & 15.56 & 5 & 11.11 & 12 & 13.33 & & \\
& & & & ASA & & & & \\
I & 32 & 71.11 & 36 & 80.00 & 68 & 75.56 & & \\
II & 13 & 28.89 & 9 & 20.00 & 22 & 24.44 & 0.963 & 0.327 \\
\hline
\end{tabular}


Table 2. Comparing the level of sedation between the two groups based on Ramsay sedation scale. Non Significant $>0.05$; Significant $<0.05^{*}$; Highly Significant $<0.001^{*}$.

\begin{tabular}{|c|c|c|c|c|c|c|c|}
\hline \multirow{2}{*}{ Ramsay sedation scale } & \multicolumn{3}{|c|}{ Group O } & \multicolumn{2}{|c|}{ Group N } & \multicolumn{2}{|c|}{ Total } \\
\hline & score & $\mathrm{n}$ & $\%$ & $\mathrm{n}$ & $\%$ & $\mathrm{n}$ & $\%$ \\
\hline Anxious or restless or both & 1 & 0 & 0.0 & 0 & 0.0 & 0 & 0.0 \\
\hline Cooperative, orientated and tranquil & 2 & 28 & 62.2 & 0 & 0.0 & 28 & 31.1 \\
\hline Responding to commands & 3 & 17 & 37.8 & 34 & 75.6 & 51 & 56.7 \\
\hline Brisk response to stimulus & 4 & 0 & 0.0 & 11 & 24.4 & 11 & 12.2 \\
\hline Sluggish response to stimulus & 5 & 0 & 0.0 & 0 & 0.0 & 0 & 0.0 \\
\hline No response to stimulus & 6 & 0 & 0.0 & 0 & 0.0 & 0 & 0.0 \\
\hline Total & & 45 & 100.0 & 45 & 100.0 & 90 & 100.0 \\
\hline $\mathrm{X}^{2}$ & & \multicolumn{6}{|c|}{44.667} \\
\hline $\mathrm{P}$-value & & \multicolumn{6}{|c|}{$<0.001^{* *}$} \\
\hline
\end{tabular}

Table 3. Parenteral separation anxiety scale.

\begin{tabular}{|c|c|c|c|c|c|c|c|}
\hline \multirow{2}{*}{ parenteral separation anxiety scale } & \multicolumn{3}{|c|}{ Group O } & \multicolumn{2}{|c|}{ Group N } & \multicolumn{2}{|c|}{ Total } \\
\hline & scale & $\mathrm{n}$ & $\%$ & $\mathrm{n}$ & $\%$ & $\mathrm{n}$ & $\%$ \\
\hline Child separate easily & 1 & 4 & 8.9 & 40 & 88.9 & 44 & 48.9 \\
\hline Child whimpers, but easily assured & 2 & 39 & 86.7 & 4 & 8.9 & 43 & 47.8 \\
\hline $\begin{array}{l}\text { Cries and difficult to be assured but not } \\
\text { clinging to parents }\end{array}$ & 3 & 2 & 4.4 & 1 & 2.2 & 3 & 3.3 \\
\hline Crying but clinging to the parents & 4 & 0 & 0.0 & 0 & 0.0 & 0 & 0.0 \\
\hline Total & & 45 & 100.0 & 45 & 100.0 & 90 & 100.0 \\
\hline \multirow{2}{*}{ Chi-square } & & \multicolumn{6}{|c|}{58.276} \\
\hline & & \multicolumn{6}{|c|}{$<0.001^{\star *}$} \\
\hline
\end{tabular}

Table 4. Mask acceptance during anaesthesia.

\begin{tabular}{lccccccc}
\hline \multirow{2}{*}{ Mask acceptance during anaesthesia } & \multicolumn{3}{c}{ Group O } & \multicolumn{2}{c}{ Group N } & \multicolumn{2}{c}{ Total } \\
\cline { 2 - 9 } & scale & $\mathrm{n}$ & $\%$ & $\mathrm{n}$ & $\%$ & $\mathrm{n}$ & $\%$ \\
\hline Child is calm, cooperative, or asleep & 1 & 10 & 22.2 & 33 & 73.3 & 43 & 47.8 \\
$\begin{array}{l}\text { Moderate fear of the mask } \\
\text { Manageable with reassurance }\end{array}$ & 2 & 31 & 68.9 & 9 & 20.0 & 40 & 44.4 \\
Cries, combative and needs restraining & 3 & 4 & 8.9 & 3 & 6.7 & 7 & 7.8 \\
Total & & 45 & 100.0 & 45 & 100.0 & 90 & 100.0 \\
\multicolumn{1}{c}{ Chi-square } & & & & & 24.545 & & \\
& P-value & & & & $<0.001^{* *}$ & & \\
\hline
\end{tabular}

After the end of the procedure and while the patients were in the postanesthetic care units [PACU], the Modified Aldrete recovery score done on a $10 \mathrm{~min}$. time scale for $30 \mathrm{~min}$.

At 10 minutes a total of 70 patients were discharged. 40 patients from $\mathrm{O}$ group 
[88.9\%] vs. 30 patients from group N. At 20 min 9 patients from the group $\mathrm{N}$ [20\%] were discharged vs. 3 patients from group O [6.7\%]. At 30 min. 2 patients were discharged from group $\mathrm{O}$ while 6 patients were discharged from group $\mathrm{N}$ as shown in Figure 1.

Timing of the hospital discharge from their ward show a significant statistical difference at $15 \mathrm{~min} 77.8 \%$ of the patients in group $\mathrm{O}$ were discharged while the remaining $17.8 \%$ discharged at $30 \mathrm{~min}$. while $46.7 \%$ in group $\mathrm{N}$. were discharged at $15 \mathrm{~min}$. discharged in group $\mathrm{O}$ in comparison to $37.8 \%$ at $30 \mathrm{~min}$. as shown in Figure 2.

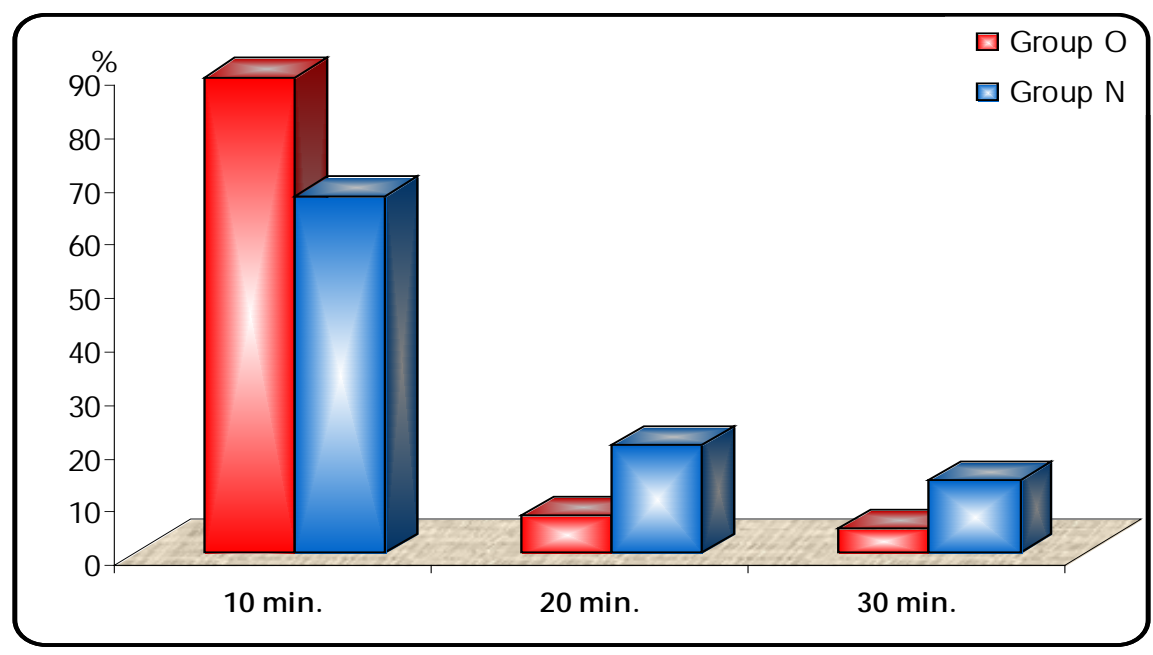

Figure 1. Shows the percentage of the patient discharged from the PACU at 10, 20 and 30 min. At 10 minutes a total of 70 patients were discharged. 40 patients from $\mathrm{O}$ group [88.9\%] vs. 30 patients from group N. At 20 min 9 patients from the group N [20\%] were discharged vs. 3 patients from group $\mathrm{O}$ [6.7\%]. At $30 \mathrm{~min}, 2$ patients were discharged From group $\mathrm{O}$ while 6 patients were discharged from group $\mathrm{N}$.

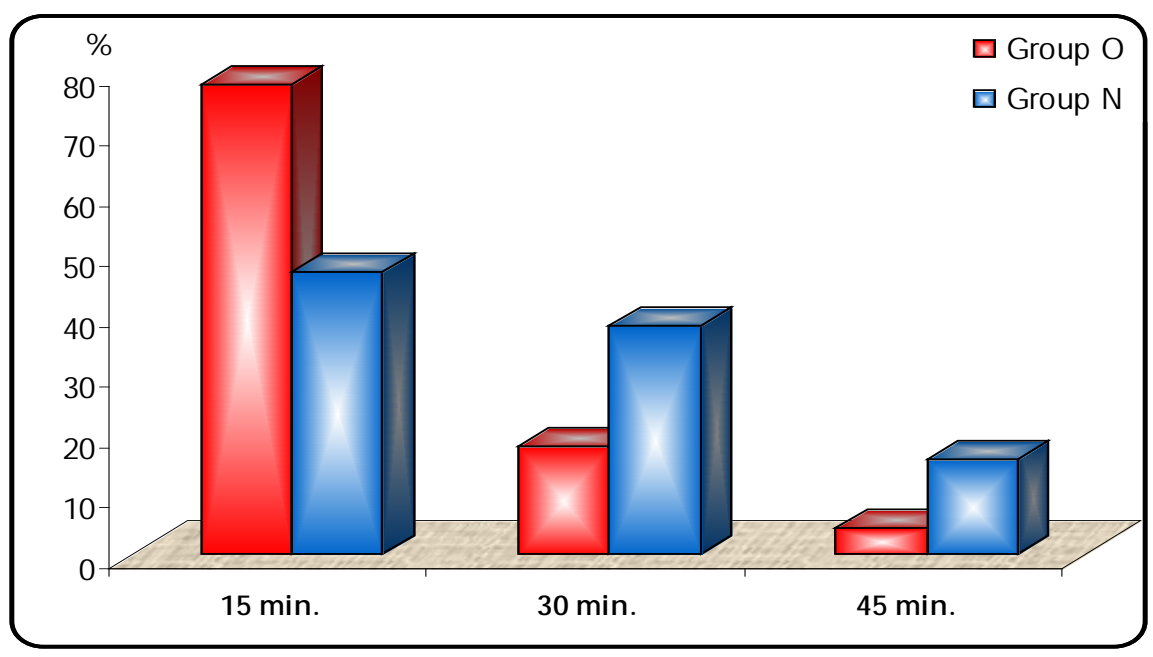

Figure 2. Show the relationship between percentage of patients disharged from the hospital and the time of discharge. At 15 min $77.8 \%$ of the patients in group $\mathrm{O}$ were discharged while the remaining $17.8 \%$ discharged at $30 \mathrm{~min}$. while $46.7 \%$ in group N. were discharged at $15 \mathrm{~min}$. discharged in group $\mathrm{O}$ in comparison to $37.8 \%$ at $30 \mathrm{~min}$. 
The parent satisfaction was assessed by the time the children were going home, $50 \%$ of the parents were satisfied with the sedation level and the route as well and reported the technique as excellent according to parent satisfaction score, $77.7 \%$ were belonging to group $\mathrm{O}$ and $22.2 \%$ were belonging to group $\mathrm{N}$, a total of $2.2 \%$ didn't accept the technique and were not satisfied [Table 5].

Table 5. Parent satisfaction score.

\begin{tabular}{|c|c|c|c|c|c|c|c|}
\hline \multirow{2}{*}{ Parent satisfaction score } & \multicolumn{3}{|c|}{ Group O } & \multicolumn{2}{|c|}{ Group N } & \multicolumn{2}{|c|}{ Total } \\
\hline & scale & $\mathrm{n}$ & $\%$ & $\mathrm{n}$ & $\%$ & $\mathrm{n}$ & $\%$ \\
\hline Excellent & 1 & 35 & 77.78 & 10 & 22.22 & 45 & 50.00 \\
\hline Acceptable & 2 & 9 & 20.00 & 34 & 75.56 & 43 & 47.78 \\
\hline Un acceptable & 3 & 1 & 2.22 & 1 & 2.22 & 2 & 2.22 \\
\hline Total & & 45 & 100.0 & 45 & 100.0 & 90 & 100.0 \\
\hline Chi-square & & \multicolumn{6}{|c|}{28.424} \\
\hline $\mathrm{P}$-value & & \multicolumn{6}{|c|}{$<0.001^{\star *}$} \\
\hline
\end{tabular}

\subsection{Discussion}

It is worth mentioning that this study was conducted on the children aged between 2 to 6 years old to test the potency of a two mixture of drugs and the effect of the mixture on the children preoperative anxiety, separation, mask acceptance, analgesic requirement as well as the postoperative discharge criteria.

The combination of the sedative and anxiolytic characteristics is believed to create a calming effect which makes children less anxious at the time of separation from their parents and mask placement [15]. Finley et al. [15] showed that a midazolam-induced decrease in anxiety was effective for children with higher baseline levels of anxiety.

Many authors have searched for the ideal pre-anesthetic medication and for the ideal route. The premedication must be acceptable, and atraumatic route of administration should be available [16] [17] [18].

The problem with oral midazolam is that it has a bitter taste. In a study bySheta and Al Sarheed [14] apple syrup was used as a carrier. Mishra et al. [17] mixed IV midazolam with honey [5 times the drug volume], which was well accepted by most of their subjects, in our study we have mixed midazolam with either flavoured paracetamol for oral preparation or with ketamine for nasal preparation.

Adding paracetamol to oral preparation in addition to alleviating the bitter taste of midazolam it has analgesic effect, also many researchers recommended the addition of midazolam to ketamine to make use of ketamine as potent analgesic in the intraoperative as well as the postoperative analgesia and consequently decreasing postoperative agitation and speed up postoperative discharge.

The current study reveals that, the combination of midazolam and ketamine is comparable to the combination of midazolam and paracetamol regarding the 
level of sedation [62.2\% ramsay score 2 in group O vs 75.6\% ramsay score 3 in group $N$ ], mask acceptance [68.9\% were 2 on the mask acceptance scale vs $73.3 \%$ in group $O$ were 1 on the scale in group $N]$ and parenteral separation score [86.7\% were 2 in group $O$ vs. $88.9 \%$ achieve 1], but the addition of ketamine to midazolam made the patients in the nasal group in a deeper level of sedation, higher mask acceptance scale and better parenteral separation score this is similar to the results of the study done by Aktham et al. [19].

In our study we found that the recovery time was faster in the midazolam and paracetamol oral group and the patients achieved higher Aldrete scoring in a shorter time where $88.9 \%$ from group $\mathrm{O}$ vs. $66.7 \%$ patients from group $\mathrm{N}$ were discharged from the PACU at $10 \mathrm{~min}$. and the patients discharged earlier from the hospital [at 15 min $77.8 \%$ of the patients in group o were discharged vs. $46.7 \%$ in group $N$ ]. This does not meet the results in the study done by Verma et al. [16] On comparing the effect of oral and nasal midazolam, they stated that the recovery times [11.63 \pm 4.19 minutes in nasal group vs. $25.20 \pm 9.36$ minutes in the oral group], and post-anesthesia recovery scores were better in the nasal spray group and this was same in the clinical study done by Sheta and AlSarheed [14] where they used oral midazolam as a premedication for dental care, The delay in the nasal route in our study could be attributed to the addition of ketamine in the nasal group

The oral midazolam and paracetamol was much more acceptable than the nasal midazolam and ketamine route by the child and achieved a higher parent satisfaction score, this is similar to the result of Verma et al. [16] who stated that the children better accepted the drug when administered orally than when administered intranasally. Despite this, the intranasal route has a satisfactory sedation level in a shorter time.

\section{Conclusion}

The combination of "midazolam and paracetamol" via oral route is comparable to the combination of "midazolam and ketamine" via nasal route in the level of sedation achieved, easiness of child separation, mask acceptance; however, "midazolam and paracetamol" could achieve a higher parents satisfaction and earlier postoperative discharge.

\section{References}

[1] Kain, Z.N., Mayes, L.C., O’Connor, T.Z. and Cicchetti, D.V. (1996) Preoperative Anxiety in Children. Predictors and Outcomes. Archives of Pediatrics \& Adolescent Medicine, 150, 1238-1245. https://doi.org/10.1001/archpedi.1996.02170370016002

[2] Kain, Z.N., Mayes, L.C., Caldwell-Andrews, A.A., Karas, D.E., and McClain, B.C. (2006) Preoperative Anxiety, Postoperative Pain, Andbehavioral Recovery in Young Children Undergoing Surgery. Pediatrics, 118, 651-658. https://doi.org/10.1542/peds.2005-2920

[3] Kain, Z.N., Caldwell, A., Maranets, I., Wang, S., Gaal, G., McClain, B. and Mayes, L. (2004) Preoperative Anxiety, Emergence Delirium and Postoperative Maladaptive 
Behaviors: Are They Related? A New Conceptual Framework. Anesthesia \& Analgesia, 99, 1648-1654. https://doi.org/10.1213/01.ANE.0000136471.36680.97

[4] McCann, M. and Kain, Z. (2001) Management of Preoperative Anxiety in Children: An Update. Anesthesia \& Analgesia, 93, 98-105.

https://doi.org/10.1097/00000539-200107000-00022

[5] Kanto, J., Watanabe, H. and Namiki, A. (1996) Pharmacological Premedication for Anaesthesia. Acta Anaesthesiologica Scandinavica, 40, 982-990. https://doi.org/10.1111/j.1399-6576.1996.tb05616.x

[6] Heller, A.R. and Koch, T. (2015) Presurgery Sedation and Patient Experience. JAMA, 313, 2379-2380. https://doi.org/10.1001/jama.2015.5516

[7] Kain, Z.N., Caldwell-Andrews, A.A., Krivutza, D.M., Weinberg, M.E., Wang, S.M. and Gaal, D. (2004) Trends in the Practice of Parental Presence during Induction of Anesthesia and the Use of Preoperative Sedative Premedication in the United States, 1995-2002: Results of a Follow-Up National Survey. Anesthesia \& Analgesia, 98, 1252-1259. https://doi.org/10.1213/01.ANE.0000111183.38618.D8

[8] Steeds, C. and Orme, R. (2006) Premedication. Anaesthesia \& Intensive Care Medicine, 7, 393-396. https://doi.org/10.1053/j.mpaic.2006.08.002

[9] Palmer, J. (2012) Premedication. Anaesthesia \& Intensive Care Medicine, 13, 525 527. https://doi.org/10.1016/j.mpaic.2012.08.019

[10] Bucx, M., Krijtenburg, P. and Kox, M. (2016) Preoperative Use of Anxiolytic-Sedative Agents; Are We on the Right Track? Journal of Clinical Anesthesia, 33, 135-140. https://doi.org/10.1016/j.jclinane.2016.03.025

[11] Kain, Z.N., Caldwell-Andrews, A.A., Krivutza, D.M., et al. (2004) Trends in the Practice of Parental Presence during Induction of Anesthesia and the Use of Preoperative Sedative Premedication in the United States, 1995-2002: Results of a Followup National Survey. Anesthesia \& Analgesia, 98, 1252-1259. https://doi.org/10.1213/01.ANE.0000111183.38618.D8

[12] Philip, D., Bailey and John, L. (2005) Preinduction Techniques for Pediatric Anesthesia. Anaesthesiology, 18, 265-269.

[13] Lerman, J. (2004) Inhalational Anesthetics. Pediatric Anesthesia, 14, 380-383. https://doi.org/10.1111/j.1460-9592.2004.01334.x

[14] Sheta, S.A. and Al Sarheed, M. (2009) Oral Midazolam Premedication for Children Undergoing General Anaesthesia for Dental Care. International Journal of Pediatrics, Article ID: 274380, 1-7. https://doi.org/10.1155/2009/274380

[15] Finley, G.A., Stewart, S.H., Buffett-Jerrott, S., Wright, K.D. and Millington, D. (2006) High Levels of Impulsivity May Contraindicate Midazolam Premedication in Children. Canadian Journal of Anesthesia, 53, 73-78. https://doi.org/10.1007/BF03021530

[16] Verma, R.K., Paswan, A., Anisa, D. and Gupta, S. (2012) Premedication with Midazolam Nasal Spray: An Alternative to Midazolam Oral Dose in Children. Anesthesiology and Pain Management. Anesthesiology and Pain Medicine, 1, 248-251. https://doi.org/10.5812/aapm.4567

[17] Mishra, L.D., Sinha, G.K., Bhaskar, Rao, P., Sharma, V., Satya, K. and Gairola, R. (2005) Injectable Midazolam as Oral Premedicant in Pediatric Neurosurgery. Journal of Neurosurgical Anesthesiology, 17, 193-198. https://doi.org/10.1097/01.ana.0000181719.86978.05

[18] Bjorkman, S., Rigemar, G. and Idvall, J. (1997) Pharmacokinetics of Midazolam Given as an Intranasal Spray to Adult Surgical Patients. British Journal of Anaesthe- 
sia, 79, 575-580. https://doi.org/10.1093/bja/79.5.575

[19] Aktham, S., Assem, M., Osama, S., Abla, A., Heba, M. and Fayrouz, S. (2016) Premedication with Nasal Sedation as an Aid for Behavior Management in Dental Procedures for Children. Journal of Anesthesia \& Clinical Research, 8, 3.

Submit or recommend next manuscript to SCIRP and we will provide best service for you:

Accepting pre-submission inquiries through Email, Facebook, LinkedIn, Twitter, etc. A wide selection of journals (inclusive of 9 subjects, more than 200 journals)

Providing 24-hour high-quality service

User-friendly online submission system

Fair and swift peer-review system

Efficient typesetting and proofreading procedure

Display of the result of downloads and visits, as well as the number of cited articles

Maximum dissemination of your research work

Submit your manuscript at: http://papersubmission.scirp.org/

Or contact ojanes@scirp.org 